\title{
Rural Transformation in Terms of Socio-Economic Status and Household Consumption Pattern: A Case Study of the Villages Azadnagar, Audali and Tilpuri-1 of Udhamsing Nagar District of Uttarakhand, India
}

\author{
Papai Barman* \\ Jawaharlal Nehru University, New Delhi, India
}

\begin{abstract}
*Corresponding Author: Papai Barman, Jawaharlal Nehru University, New Delhi, India
Abstract: Though, there is improvement found at district and state level in terms of education, income, GSDP etc. still there are disparities across the villages in Uttarakhand. Hence the present study tried to capture the village level consumptions pattern by income, caste and religion and rural transformation. The study also tried to document the factors, which inhibiting to transformation of rural area in Uttarakhand. The bivariate and Multivariate poison regression depicts that some particular community's people (SC and ST) are deprived from all development. The analysis do not show strong evidence, but there is found role of religion, income and villages. So to developed district and state level, the government should focus on the village level disparity. There should be some programme for creating awareness among people about humanity and standard life like urban culture. So, there is need to take or looking at the vulnerable people or group. It can be done by taking suitable programme and policy.
\end{abstract}

Keywords: Disparities; Expenditure; Cultural and Religion Variation; Rigid Caste System; Inequality; Rural Transformation.

\section{BACKGROUND}

Socio-economic status and household consumption of any region are the major factors to understand the living standard. The socio-economic status comprises social category, religion, income, education, occupation, consumption, and health etc. The household consumption comprises foods expenditure, household assets expenditure, education expenditure etc. Different social categories, different religions, different income people are used different types assets, foods, education quality etc. Socioeconomic status expressing countries or any region quality of life (J. Arne, at al 2005). Foods and any kind of consumptions pattern are also shown household's or any region's socio-economic status (A. Druckman, T. Jackson 2008). India is known for its divers culture, difference social norms etc. There is also difference across the region. Northern India is totally different from southern India, it is known for rigid social cultural norms (Schwartzberg 1965 and Sebring 1972). Along with caste and religion, the region has improved its economic condition, reduced inequality, and reduced poverty over the year. For example, poverty of Uttarakhand declined by three times from $32.7 \%$ (2004-05) to $11.3 \%$ (2011-12). In contrary, there is also impressive growth in terms of gross state domestic product (GSDP), it is 9\% during the period 2001-02 to 2011-12 (at 2004-05 prices). As a result, real per capita income of the state increased 4.5 times from Rs. 19,164 in 2001-02 to Rs. 92,911 in 2011-12 (Mamgain and uryanarayana 2017). There is also improve in terms of education level, it reached $71.6 \%$ (2001) to $78.8 \%$ (2011). In Uttarakhanmd, 70\% people belong to rural and rest of urban. There is also found inequality in terms education, poverty, and employment by the region. The unemployment rate is more than national, it is 3.1\%. An adherence, 15-29 age group people (Young) unemployment rate is more, it is $14.3 \%$. There are both things positive and negative are found. Now the main is that rural condition along with above conditions. The word 'Rural transformation' means positive process into the development of rural area. It basically talks about the taking the features of urban areas (Ohlan 2016). In urban area, we found that there is no religious boundary, caste boundary, income wise boundary, all people living together with their busy life. Transformation of either urban or rural involves in changing of education level, income level, and social-cultural level. Along with 
these, some caste and religious people are discriminated in India by education, job, income etc. (Ambetkar 1936).

Rural transformation is happened when there is found change in terms education, income inequality, caste and religious norms and living style pattern (foods consumption, assets consumption etc.). The study area is Udhamsing Nagar district of Uttarakhand. Basically, the state and districts are famous for its cultural and religious norms. Now question is that, is these norms are rigid or flexible. Is the districts villages are transforming same as the existing literature stated. If the norms are flexible then there could be found sign of rural transformation. Is there any rural transformation is happened in terms of household consumption? If it is, then what is pattern? If it is not, then what factors play role as averse to transformation? From the above questions and query, the present study tried to document the foods, assets and household expenditure pattern in terms of the caste, religion and income. The study also tried to document the factor effecting on the expenditure.

\section{MATERIALS AND METHODS}

\subsection{Data}

The study has been used the primary data collected from the villages Azadnagar, Audali and Tilpuri-1 of Udhamsing Nagar District of Uttarakhand, $2^{\text {nd }}$ December to $22^{\text {nd }}$ December 2017. The data collection is started by the Stratified Random Sampling. Based on this, above three villages are selected. There are many methods are used to collect the data. All methods are selected based on the objective purpose. The study used both qualitative and quantitative techniques. The methods are used such as Transect Walk, Social Mapping, Focus Group Discussion (FGD), Key Information Interview (KII) and household level questionnaire. From the three villages, there are 273 samples taken. In contrary, 113 samples from Azadnagar, 115 from Audali and 45 samples from the Tilpuri-1 village.

\subsection{Variables}

The outcome variables in the study are foods, assets and household expenditure. Household expenditure is the overall (foods and assets) expenditure. Predictor variables used in the study are caste (SC, ST, OBC and General), religion (Hindu and Sikh) and income (for details, see Table 1 and 2).

\subsection{Methodology}

To assess the objective different type methodologies are selected. The study is used both qualitative and quantitative method. Some statistical tools are also used. The study is used descriptive statistics to proclaim the sample distribution. Bivariate analysis is used to understand the pattern of Foods, assets and household expenditure and transformation. The study by Jha (1997) argued that northern India has rigid caste and religion norms, along with untouchability. It is known that rigid caste and religion norms and untouchability create a social exclusion system. The study used the statement to assess the transformation of rural. The study assumed that lower the variation higher the transformation. For example, if there is less variation among different caste (SC, ST, OBC and General), religion (Hindu and Sikh) and income groups in terms of Foods, assets and household expenditure, then it implies the abolish of rigid systems or norms or exclusion system. The study also used the multivariate Poisson regression model to document the effect of the different background characteristics on changed or stalled the transformation of rural. Whole quantitative work is done by using STATA release 14. Additionally, the study used the information collected through 3 FGDs, 4 KII and 3 Social Mapping to give supporting evidence. A FGD group is comprised of 7-8 persons from different background. All persons of a group and KII were above 20 ages. All groups are comprised of both man and woman. Three social mapping were done based on their view and our view.

\section{Results}

\subsection{Different Sample Characteristics}

The table 1 presents the sample distribution of the different selected variables. It shows that among all villages, $48 \%$ people belongs to the ST and $21 \%$ to the SC, OBC is $12 \%$ and General is $19 \%$. It also shows that $92 \%$ people are belongs to Hindu community and rest are the Sikh. In contrary, 37\% people have more than 1 lacks income per annual. The spending behaviour among the people is different. About $37 \%$ people spending above 3 thousands on foods per moths. In contrary $42 \%$ people spending on assets above 10 thousand per months. 
Influence of Negotiation Structure on the Success of Consociational Democracy in the Management of Ethno-Political Conflicts in Mandera County, Kenya

Table1: Percentage Distribution of the Background Characteristics

\begin{tabular}{|l|l|l|l|}
\hline Background Characteristics & \multicolumn{1}{|c|}{ Percentage } & \multicolumn{2}{c|}{ 95\% Confidence Interval } \\
\hline Caste & \multicolumn{2}{|c|}{} & \multicolumn{2}{c|}{} \\
\hline SC & 21 & 16 & 26 \\
\hline ST & 48 & 42 & 54 \\
\hline OBC & 12 & 9 & 17 \\
\hline GEN & 19 & 15 & 24 \\
\hline Religion & & & \\
\hline Hindu & 92 & 88 & 95 \\
\hline Sikh & 08 & 05 & 12 \\
\hline Income (per annual) & 13 & & \\
\hline$<20000$ & 31 & 10 & 18 \\
\hline $20000-50000$ & 19 & 26 & 37 \\
\hline $50000-100000$ & 37 & 14 & 24 \\
\hline $100000-2000000$ & & 32 & 43 \\
\hline Foods Expenditure & 19 & & \\
\hline$<3000$ & 37 & 15 & 25 \\
\hline $3000-5000$ & 35 & 32 & 43 \\
\hline $5000-10000$ & 08 & 30 & 41 \\
\hline $10000-20000$ & 35 & 05 & 12 \\
\hline Assets Expenditure & 41 & & \\
\hline$<10000$ & 14 & 29 & 41 \\
\hline $10000-30000$ & 10 & 35 & 47 \\
\hline $30000-50000$ & & 11 & 19 \\
\hline $50000-500000$ & & 07 & 14 \\
\hline
\end{tabular}

Note: $\mathrm{SC}=$ Scheduled Caste; $\mathrm{ST}=$ Scheduled Tribe; $\mathrm{OBC}=$ Backward Class; Other= General.

Source: Computed from Primary data file.

The scenario at village level is different. The table 2 shows that $80 \%$ people belongs to ST in Tilpuri and Audali village, there are very few people from SC, OBC and General. In Azadnagar, most of people belong to General and SC. The context of religion, Tilpuri village has $100 \%$, Audali has $88 \%$ and Azadnagar has 92\% Hindu people. In contrary, 58\% people have income more than 1 lacks in Azadnagar village, while Tilpuri and Audali villages only $37 \%$ and $16 \%$ people have more than 1 lacks income respectively.

Table2: Percentage Distribution of the Background Characteristics by Village

\begin{tabular}{|l|l|l|l|}
\hline \multicolumn{1}{|l|}{ Background Characteristics } & Tilpuri (n=45) & Audali (n=115) & Azadnagar (n=113) \\
\hline Caste & 8.89 & 3.48 & 42.48 \\
\hline SC & 82.22 & 80.87 & 0.88 \\
\hline ST & 2.22 & 14.78 & 14.16 \\
\hline OBC & 6.67 & 0.87 & 42.48 \\
\hline GEN & \multicolumn{1}{l|}{} \\
\hline Religion & 100.00 & 88.70 & 92.04 \\
\hline Hindu & 0.00 & 11.30 & 7.96 \\
\hline Sikh & \multicolumn{1}{l|}{} \\
\hline Income (per annual) & 15.56 & 21.74 & 3.54 \\
\hline$<20000$ & 31.11 & 49.57 & 11.50 \\
\hline $20000-50000$ & 15.56 & 12.17 & 26.55 \\
\hline $50000-100000$ & 37.78 & 16.52 & 58.41 \\
\hline $100000-2000000$ & &
\end{tabular}

Source: Computed from Primary data file.

\subsection{Differential Expenditure by Background Characteristics}

Table 3 presents means expenditure pattern by background characteristics. It implies that the Foods expenditure among SC people is found high it is an average 6.5 thousand per months followed by general 5.8, OBC 5.5 and ST 5.2 thousands. In contrary, assets expenditure is found high among General caste people, it is 6.3 thousand per months followed by SC 4.5, OBC 3.0 and ST 2.8 
Influence of Negotiation Structure on the Success of Consociational Democracy in the Management of Ethno-Political Conflicts in Mandera County, Kenya

thousands. Similar pattern is found in terms of overall expenditure or Household expenditure. In the context of religion, different story is found. Foods expenditure pattern is same in the both community, while it is different in terms of assets and household expenditure. The table shows that around double expenditure pattern among ST community as compare to Hindu. For example, the average expenditure in household is 70 thousand per month among ST people, while it is only 42 thousand among Hindu. An adherence of income level wise expenditure, it is found that those have high income they have spending more on foods, assets and on households. Although three village has different kind of socio-cultural and economic pattern, foods expenditure patterns is found almost same, only Azadnagar has showing more expenditure. In terms of assets expenditure, average 52 thousands expenditure is found in Azadnagar, followed by Tlupuri 48 and Audali 22 thousands. In overall household expenditure, it is found that Azadnagar expenditure is average 58 thousand per months, while 54 in Tilpuri and 27 in Audali.

Table3: Mean Household Expenditure Pattern

\begin{tabular}{|l|l|l|l|}
\hline Background Characteristics & Foods Expenditure & Assets Expenditure & Household Expenditure \\
\hline Caste & $6518(5386-7649)$ & $45607(21419-69796)$ & $52125(27538-76712)$ \\
\hline SC & $5283(4722-5844)$ & $28588(17745-39431)$ & $33871(23014-44728)$ \\
\hline ST & $5580(4624-6536)$ & $30765(21955-39574)$ & $36345(27457-45233)$ \\
\hline OBC & $5843(4917-6768)$ & $63288(32642-93935)$ & $69131(38474-99789)$ \\
\hline GEN & $5695(5270-6121)$ & $36665(27885-45446)$ & $42361(33504-51218)$ \\
\hline Religion & $5501(3707-7295)$ & $65136(4958-125315)$ & $70637(10578-130697)$ \\
\hline Hindu & \multicolumn{4}{|l|}{} \\
\hline Sikh & $4200(3854-4546)$ & $9583(4452-14715)$ & $13784(8513-19054)$ \\
\hline Income (per annual) & $5216(4661-5770)$ & $12952(11069-14836)$ & $18168(16247-20090)$ \\
\hline$<20000$ & $6245(5254-7236)$ & $39471(20815-58127)$ & $45716(27112-64319)$ \\
\hline $20000-50000$ & $6301(5451-7151)$ & $70490(48692-92289)$ & $76792(54897-98686)$ \\
\hline $50000-100000$ & $5403(4268-6539)$ & $48578(18656-78500)$ & $53981(23606-84356)$ \\
\hline $100000-2000000$ & $5341(4751-5931)$ & $21922(12950-30894)$ & $27262(18274-36251)$ \\
\hline Village & $6135(5472-6798)$ & $52469(35790-69148)$ & $58604(41902-75306)$ \\
\hline Tilpuri
\end{tabular}

Source: Computed from Primary data file.

\subsection{Possible Factor Effecting on Expenditure}

Table 4 presents the results from Poisson regression. The present study used three models to document the factors effect on the rural transformation. The first model shows the relationships between background characteristics and foods expenditure. The second model shows the relationships between background characteristics and assets expenditure. The third model shows the relationships between background characteristics and household expenditure. The first model shows that ST, OBC and General people foods expenditure is around $13 \%$ less than SC people. In contrary, the higher income people expending more on foods than reference category. Audali village expenditure is found more than Tilpuri village. The second model shows that the assets expenditure is $0.24 \%$ high among General people than SC people. In the religion context, Sikh people assets expenditure is $100 \%$ higher than SC people. It also shows that higher income people expending more on assets than reference category. An adherence of village, the model shows that Audali and Azadanagar village assets expenditure is around 35\% less than Tilpuri village. Similar kind of result is found in terms of model three.

Table4: Multivariate Poisson Regression Model

\begin{tabular}{|l|l|l|l|}
\hline Background Characteristics & \multicolumn{1}{|c|}{ Model 1 (IRR) } & \multicolumn{1}{|c|}{ Model 2 (IRR) } & \multicolumn{1}{c|}{ Model 3 (IRR) } \\
\hline Caste & & & \\
\hline SC $\mathbb{~}$ & 1.000 & 1.000 & 1.000 \\
\hline ST & $0.852^{* * *}$ & $0.952^{* * *}$ & $0.958^{* * *}$ \\
\hline OBC & $0.870^{* * *}$ & $0.731^{* * *}$ & $0.737^{* * *}$ \\
\hline GEN & $0.870^{* * *}$ & $1.024 * * *$ & $1.010^{* * *}$ \\
\hline Religion & & & \\
\hline
\end{tabular}


Influence of Negotiation Structure on the Success of Consociational Democracy in the Management of Ethno-Political Conflicts in Mandera County, Kenya

\begin{tabular}{|c|c|c|c|}
\hline Hindu ${ }^{\circledR}$ & 1.000 & 1.000 & 1.000 \\
\hline Sikh & $0.997 * * *$ & $2.506 * * *$ & $2.297 * * *$ \\
\hline \multicolumn{4}{|c|}{ Income (per annual) } \\
\hline $\begin{array}{l}<20000 \AA \\
\end{array}$ & 1.000 & 1.000 & 1.000 \\
\hline $20000-50000$ & $1.230 * * *$ & $1.300 * * *$ & $1.275^{* * * *}$ \\
\hline $50000-100000$ & $1.484 * * *$ & $4.220 * * *$ & $3.398 * * *$ \\
\hline $100000-2000000$ & $1.501 * * *$ & $7.062 * * *$ & $5.394 * * *$ \\
\hline \multicolumn{4}{|l|}{ Caste } \\
\hline Tilpuri® & 1.000 & 1.000 & 1.000 \\
\hline Audali & $1.059 * * *$ & $0.651 * * *$ & $0.694 * * *$ \\
\hline Azadnagar & $0.982 * * *$ & $0.681 * * *$ & $0.722 * * *$ \\
\hline \multicolumn{2}{|c|}{ Number of observation } & \multicolumn{2}{|l|}{273} \\
\hline \multicolumn{2}{|l|}{ LR chi2(9) } & \multicolumn{2}{|l|}{5584870} \\
\hline \multicolumn{2}{|l|}{ Prob>chi2 } & \multicolumn{2}{|l|}{0.000} \\
\hline \multicolumn{2}{|l|}{ Log likelihood $=$} & \multicolumn{2}{|l|}{-5354984} \\
\hline
\end{tabular}

Note: @: Reference Category; ***p $<0.001, * * \mathrm{p}<0.01,{ }^{*} \mathrm{p}<0.05$.

Source: Computed From Primary Data File.

\section{DISCUSSION}

From the descriptive statistics, there is little difference found in terms of foods expenditure among different all background characteristics people. In contrary, there is huge difference found in terms of assets and household expenditure among difference backgrounds people. It is also shows the huge variation between the villages. The Multivariate Poisson Regression shows that there is little variation found among the different caste people in terms of foods, assets and household expenditure. The huge variation is found in terms of religion, income and village.

Additionally to support the above quantitative arguments, qualitative information is used. The FGD-1 was conducted in Azadnaar village among women from different background characteristics. The participants asserted:

"The village has no issue with caste, job, and all people got house from IGWY (Indira Gandhi AwasYojana). They are living with cooperatively etc".

One interesting thing is that, whatever response and discussion were happened, all were done among two higher class people (Punjabis) women. Others were just in silent. When they were tried to speak, these two women created barrier. The other women couldn't tell their own problem. Actually whole the FGD were done only by the two higher class people (Punjabis) women.

FGD-2 was conducted in Audali village among men and women from different background characteristics (Most of are from the ST community). The participants asserted:

"The village has some issue with caste, job. Punjabis are centre of the village. They have own job market and the SC and ST people work on these market. Although they got same amount of lands (15 acre) and opportunities".

This is really found in the village Audali. Although there are ST people is more but domination is found from the Punjabis.

FGD-3 was conducted in Tilpuri village among men from different background characteristics (Most of are from the Higher class people (Punjabis) community. The participants asserted:

"The village has no issue with caste, job, and all people got house from IGWY (Indira Gandhi Awas Yojana). They are living with cooperatively. They are living far away from the main road, that's why they are not able to business. They only depend on agriculture. Agriculture is done by most of SC and ST community people and those are from higher class people (Punjabis) community, they prefer to go government job like military".

The Tilpuri village also talked the reality. But there is also somehow domination or barrier is found among them. From own view the village houses are found beside the road of village and most of SC and ST people house is found at the end of the village. Most of them are uneducated and they were busy with agriculture and cow and cow dunk cake. 
Influence of Negotiation Structure on the Success of Consociational Democracy in the Management of Ethno-Political Conflicts in Mandera County, Kenya

Apart from the FGD, 4KII also done. KII-1, was a Pradhan of the Azadnaar village, he stated that:

"I am the Pradhan of the village from SC community, but no one respect me. People of higher class just giving me order and they do not tried to listen to me."

KII-2, was a government primary school teacher from the Azadnagar village. She stated:

"The most of the students in the school belongs to the SC and ST people. Among them some students are those who are coming school after completion of their house work, like cleaning, washing, sometimes cocking etc. Very few students from the higher class, they are going to the English medium school, which is located $3 \mathrm{~km}$ away."

It really implies the different condition. SC and ST people and also children condition in that area is not so much good as other general people (higher class people (Punjabis)).

KII-3, was from the Audali village, she was the Pradhan of the village. She stated that:

"Few decades age they were marginalised by the Punjabis. They were just living with agriculture. There lands also brought out by the Punjabis. They became very weak in terms economic, although they were maximum in number. They were dependent on the educated Punjabis for everything official work s and other works. After that situation ST and SC people have been trying to improve their status. But today also they are dependent on the Punjabis, because of they are educated, economically developed. I am now Pradhan because of the majority of ST people. But we are behind of the Punjabis."

KII-4 was an aged (above 50 age) member of the village Tilpuri-1, he was higher class people (Punjabis) stated:

"The village have SC, ST, OBC and General people. We are living here with cooperative life. We don't have any issue with the other caste or religion people."

Based on the above information from the different people and transect work and social mapping, there are really found concern about caste and religion. In Azadanagar village, SC and ST people settled outside the village, which itself implies that the higher class people do not want them as close. Comparatively high class job and business mare doing the high class people. While SC and ST people dependent on agriculture. Same kind situation are found in terms of Audali and Tilpuri-1 village. In contrary, SC and ST people are belongs to the Non-Sikh and SC people are low class Hindu. It means there are also some kind of exclusion pattern by the high class people, Punjabis. Along with religion and caste, economic condition also is not good among SC and ST people.

Based on the above quantitative and qualitative results, it is found that there is found boundary between people by religion and villages. There is not found rigid issue related to caste. There is not found rural transformation but it is somehow in ongoing process. The study does not found any appropriate reasons, but somehow religion norms, village and income playing a great role to create hindrance on the rural transformation.

\section{CONCLUSION}

From the above discussion the study has some evidence to conclude that the people of three villages do not getting equal opportunity, equal freedom and cooperative behaviour from each other. Although state and district level, there is increase in terms of education, income, GSDP and reduced poverty but in village level it is not found. There is some kind boundary among the people based on religion. Another way, the study has not strong evidence to say that these selected factors are playing strong role. But there is role of these caste, religion and economy to inhibit the rural transformation in Uttarakhand state. There is need of further study to strongly conclude the situation.

\section{RECOMMENDATION}

Government should focus in the village or ground level by looking their educational help, programme and taking policy to transform and to abolish the boundary.

\section{NOTES}

The study assumed that lower the variation among different background people and higher the transformation. Less variation among different caste (SC, ST, OBC and General), religion (Hindu and Sikh) and income groups in terms of Foods, assets and household expenditure, then it implies the abolish of rigid systems or norms or exclusion system and transformation of rural area. 
Influence of Negotiation Structure on the Success of Consociational Democracy in the Management of Ethno-Political Conflicts in Mandera County, Kenya

\section{REFERENCES}

[1] Ambedkar B. R. 1936. Annihilation of Caste. the secretary of the Jat-Pat Todak Mandal Lahor, India.

[2] Arne J. at el .2015. Letting the (energy) Gini out of the bottle: Lorenz curves of cumulative electricity consumption and Gini coefficients as metrics of energy distribution and equity, University of California, Berkeley, USA,

[3] Berreman G. D. 1960. Caste in India and the United States. American Journal of Sociology, 66(2): 120-127.

[4] Druckma A and Jackson T. 2004, Measuring resource inequalities: The concepts and methodology for an area-based Gini coefficient.

[5] Gandhi R. S. 1980. From caste to class in Indian society. Humboldt Journal of Social Relations, 7(2): 1-14.

[6] Human Development Report of The State of Uttarakhand 2018. Directorate of Economics \& Statistics Department of Planning Government of Uttarakhand.

[7] Jha V. 1997. Caste, Untouchability and Social Justice: Early North Indian Perspective. Social Scientist, 25(11/12): 19-30.

[8] Mamgain R. P. and Suryanarayana M.H. 2017. Estimation of District level poverty in Uttarakhand, Directorate of Economics and Statistics Department of Planning Government of Uttarakhand.

[9] Mosse D. 2018. Caste and development: Contemporary perspectives on a structure of discrimination and advantage. world development, 110: 422-436.

[10] Munshi K. 2017. Caste and the Indian Economy. Cambridge Working Papers in Economics 1759, Faculty of Economics, University of Cambridge.

[11] Ohlan R. 2016. Rural Transformation in India in the Decade of Miraculous Economic Growth. Journal of Land and Rural Studies, 4(2) 1-18.

[12] Rachel P. and Pablo M. 2016. Socio-economic inequalities in the healthiness of Foods choices: Exploring the contributions of Foods expenditures.

[13] Ramna T. and Shivendra S., Increasing Inequality in the Western Indian Himalayan Region, Indian Institute of Technology Mandi, H. P., India.

[14] Samuel F. 2010. Inequality in the distribution of household expenditure in Cameroon: A Gini decomposition analysis based on the Shapley-value approach. Educational Research 1(2): 021-031.

[15] Schwartzberg J. E. 1965. The Distribution of Selected Castes in the North Indian Plain. Geographical Review, 55(4): 477-495.

[16] Sebring J. M. 19721. The Formation of New Castes: A Probable Case from North India. American Anthropologist, 74(3): 587-600.

[17] Stevenson H. N. C. 1954. Status Evaluation in the Hindu Caste System. Journal of the Royal Anthropological Institute of Great Britain and Ireland, 84(1/2): 45-65.

[18] Tulika S. et al (2017), Socio-economic status scales updated for 2017.

[19] Zacharias A. and Vakulabharanam V. 2010. Caste Stratification and Wealth Inequality in India Author links open overlay panel. World Development, 39(10) 1820-1833.

\section{AUTHOR'S BIOGRAPHY}

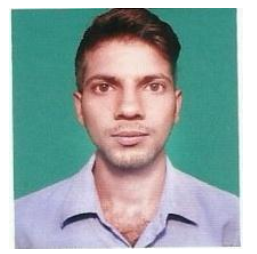

Bachelor in Geography, Gour Banga University, Malda, West Bengal, India

Master in Geography, Jawaharlal Nehtu University, New Delhi, India

Master in Population Studies, International Institute of Population sciences, Mumbai, India

Citation: Papai Barman. "Rural Transformation in Terms of Socio-Economic Status and Household Consumption Pattern: A Case Study of the Villages Azadnagar, Audali and Tilpuri-1 of Udhamsing Nagar District of Uttarakhand, India". International Journal of Humanities Social Sciences and Education (IJHSSE), vol. 6, no.9, 2019, pp. 59-65. doi: http://dx. doi.org/10.20431/2349-0381.0609006.

Copyright: () 2019 Authors. This is an open-access article distributed under the terms of the Creative Commons Attribution License, which permits unrestricted use, distribution, and reproduction in any medium, provided the original author and source are credited. 